\title{
Changing Clinical Picture of Neurosyphilis: Report of Seven Unusual Cases
}

\author{
RONALD JOFFE,* M.B., M.R.C.P. : MARTIN M. BLACK,* M.B., M.R.C.P. ; MICHAEL FLOYD,* M.B., M.R.C.P.
}

Brit. med. F., 1968, 1, 211-212

August von Wassermann was born in Bavaria just over a century ago, and perhaps it is therefore fitting to report a small group of patients in which serious diagnostic difficulties were resolved with the aid of the complement-fixation test now named after him. We also report these cases in order to draw attention to the fact that neurosyphilis, though uncommon, is not nowadays as rare as some would have us believe and that the disease may present in a variety of unfamiliar guises.

We have analysed all the cases in which a positive Wassermann reaction or Reiter test was obtained over a ninemonth period, after patients with a known history of syphilis had been excluded. During the period of study a W.R. and Reiter test was performed on 493 neurological admissions, of which seven were found to be positive. All seven patients were subsequently shown by further serological tests to have syphilis and the cases are described below.

\section{Case 1}

A 64-year-old widow was referred with a 19-year history of typical "drop attacks." Though at first infrequent they had been occurring twice weekly at the time she was first seen. The attacks had never been associated with diplopia, vertigo, or loss of consciousness. Physical examination revealed a symmetrical spastic quadriparesis and mild aortic incompetence.

Investigations.- $-\mathrm{Hb} 13.1 \mathrm{~g} .1100 \mathrm{ml}$; E.S.R. $16 \mathrm{~mm}$. in first hour. Serum +C.S.F. serology: W.R., Reiter, Treponema pallidum immobilization (T.P.I.) all positive. Lumbar puncture: C.S.F. clear, colourless fluid under normal pressure; protein $165 \mathrm{mg} . /$ $100 \mathrm{ml}$., W.B.C. $40 / \mathrm{cu}$. mm. (10\% polymorphs, $10 \%$ lymphocytes); chest $x$-ray picture: normal.

Treatment.-The patient was given a three-week course of penicillin ( 1 mega unit intramuscularly daily). Six months later she was quite well and had had no recurrence of "drop attacks."

\section{Case 2}

A 51-year-old locomotive driver experienced a visual hallucination about six weeks before his referral. He denied other complaints, but his relatives felt that there had been a recent personality change. Physical examination showed impairment of memory and a left extensor plantar response. A few days later there was marked impairment of intellect and he was clearly confabulating. For the first time both pupils showed a sluggish reaction to light but maintained a brisk response to accommodation. Deep tendon reflexes were symmetrically increased with bilateral extensor plantar responses.

Investigations.-Hb 15.7 g. $/ 100 \mathrm{ml}$; E.S.R. $52 \mathrm{~mm}$. in first hour. Serum serology: W.R., Reiter, T.P.I. all positive. Lumbar puncture: C.S.F. clear, colourless fluid under normal pressure; protein $80 \mathrm{mg} . / 100 \mathrm{ml}$; W.B.C. 12/cu. mm. (all polymorphs). Bilateral carotid angiography; no evidence of a supratentorial space-occupying lesion, but there was evidence of ventricular dilatation.

Treatment.-He was treated with penicillin (1 mega unit intramuscularly daily) for three weeks, and by the tenth day showed

- Department of Neurology, Regional Neurological Centre, Newcastle General Hospital, Newcastle upon Tyne 4 significant improvement. After leaving hospital he continued to improve and within three months had returned to work.

\section{Case 3}

A 63-year-old housewife was referred with a two-year history of increasing deafness and unsteadiness on walking. Physical examination revealed severe anosmia and perceptive deafness with a spastic paraparesis. All neck movements were painful and moderately restricted.

Investigations.-Hb $14.2 \mathrm{~g} .100 \mathrm{ml}$. ; E.S.R. $9 \mathrm{~mm}$. in first hour. Serum serology: W.R., Reiter, T.P.I. all positive. Lumbar puncture: C.S.F. clear colourless fluid under normal pressure; protein $146 \mathrm{mg} . / 100 \mathrm{ml}$., with 7 lymphocytes per cu. $\mathrm{mm}$. Myelogram: numerous disc protrusions throughout the cervical and dorsal spine.

Treatment.-She was given a three-week course of penicillin (1 mega unit intramuscularly daily). Six months later there had been no significant change in the symptoms or physical signs.

\section{Case 4}

A 58-year-old widow was referred with a three-year history of recurrent episodes of left-sided facial "spasm" as well as intermittent incoordination of her right arm. These episodes could occur independently and never lasted longer than a few minutes. She was currently receiving treatment for "varicose" leg ulcers. Physical examination revealed no abnormalities in the neurological or cardiovascular systems, but over both malleoli there were several painless "punched out" ulcers.

Investigations.- $\mathrm{Hb} 14 \mathrm{~g} . / 100 \mathrm{ml}$. ; E.S.R. $10 \mathrm{~mm}$. in first hour. Serum serology: W.R., Reiter, T.P.I. all positive. Lumbar puncture: C.S.F. clear colourless fluid under normal pressure ; protein $50 \mathrm{mg} . / 100 \mathrm{ml}$. (gammaglobulin $33 \%$ ), no pleocytosis. Chest screening: marked pulsation and dilatation of the ascending aorta with linear calcification.

Treatment.-She was treated with penicillin (1 mega unit intramuscularly daily) for three weeks. At the conclusion of therapy the gummatous ulcers had nearly healed and she had had no further attacks.

\section{Case 5}

A 67-year-old retired miner was found to have heavy glycosuria after presenting with severe balanitis. The patient volunteered that for the past three years he had become fearful of the dark because he tended to fall over. On examination he was euphoric, and psychometric testing revealed features of dementia. The right pupil was irregular, responding poorly to light, but the left pupil and optic fundi were normal. There was moderate weakness of forearm muscles and hip flexors. All deep tendon reflexes were absent, the plantars remaining flexor. Sensory testing revealed loss of vibration sense below the knees, no response to tendo-Achilles compression, and minimal impairment of joint position sense in the toes. He was moderately ataxic.

Investigations.-Hb $17 \mathrm{~g} . / 100 \mathrm{ml}$. ; E.S.R. $3 \mathrm{~mm}$. in first hour ; fasting blood sugar $292 \mathrm{mg} . / 100 \mathrm{ml}$. Serum+C.S.F serology: W.R., Reiter, T.P.I. all positive. Lumbar puncture: C.S.F. clear colourless fluid under normal pressure; protein $42 \mathrm{mg} . / 100 \mathrm{ml}$. (gammaglobulin 9\%); no pleocytosis. 
Treatment.-He was given a three-week course of penicillin (1 mega unit intramuscularly daily) and his diabetes was well controlled on a 1,000-calorie diet alone.

\section{Case 6}

A 57-year-old clerk was referred with a seven-year history of intermittent neck and shoulder pain mainly related to rotatory movements. Two years before admission he developed some slowness of his gait, and noticed that he was trailing the left foot. Examination revealed limited extension of the cervical spine, and all ranges of movement appeared to cause great discomfort. The optic fundi and pupillary reactions were normal. There was an asymmetrical spastic tetraparesis with bilateral extensor plantar responses. There was no evidence of any sensory loss, and the rest of the general examination showed no abnormality.

Investigations.-Hb 14.3 g. $/ 100 \mathrm{ml}$. ; E.S.R. $21 \mathrm{~mm}$. in first hour. Serum +C.S.F. serology: W.R., Reiter, T.P.I. all positive. Lumbar puncture: C.S.F clear colourless fluid under normal pressure; protein $90 \mathrm{mg} . / 100 \mathrm{ml}$. (gammaglobulin $33 \%$ ); no pleocytosis. $X$-ray film of cervical spine: marked degenerative changes with diminution in the C 5-6. C 6-7, C 7-T 1 intervertebral disc spaces. Myelogram: disc protrusions at the $C$ 3-4 and C 5-6 levels with arrest of the myodil columns in the extended neck position in this region.

Treatment.-He was given a three-week course of penicillin (1 mega unit intramuscularly daily), but six weeks later there had been no change in his symptoms or physical signs. Dorsal laminectomy was performed at the level of $\mathrm{C} 3,4$, and 5 and six months later there had been a considerable regression of the neurological signs.

\section{Case 7}

A 19-year-old miner was referred with a three-week history of increasing apathy and somnolence. Admission to hospital was arranged shortly after he had a major epileptic fit. On examination he lay motionless and mute but would follow the examiner's movements with his eyes. He was slow in response to commands and catatonia could be elicited. Both pupils were widely dilated and unresponsive to light. All deep tendon reflexes were depressed and the plantar responses were flexor.

Investigations.-Hb 15.4 g. $/ 100 \mathrm{ml}$., E.S.R. $20 \mathrm{~mm}$. in first hour. Serum +C.S.F. serology: W.R., Reiter, T.P.I. all positive. Lumbar puncture: C.S.F clear colourless fluid under normal pressure ; protein $109 \mathrm{mg} . / 100 \mathrm{ml}$. (gammaglobulin 15\%); sugar $58 \%$; W.B.C. $38 / \mathrm{cu}$. mm. (mainly lymphocytes). $X$-ray examination of chest and skull: N.A.D. E.E.G.: unstable, polyrhythmic record, containing a moderate generalized excess of slow activity. Changes were only compatible with a mild non-specific abnormality.

Treatment.-Penicillin 1 mega unit intramuscularly was given for three weeks. Shortly after starting treatment he had several further major epileptic fits and appeared to experience terrifying visual hallucinations. He remained mute and akinetic for about four weeks, but thereafter gradually recovered. Sensory examination then revealed wide areas of sensory loss over the nose, trunk, and perineum. He had a high-stepping gait with gross loss of joint position sense. Investigation of a persistent micturating difficulty revealed a poorly contracting bladder with an obstruction to flow at the internal sphincter. This micturating difficulty was gradually overcome by a combination of bladder training and the use of carbactol.

The patient's mother was tested serologically and she was found to have latent syphilis.

\section{Discussion}

We suggest that the Wassermann reaction today is of even greater importance than in the past. In two of the cases de- scribed the presenting clinical features were in no way characteristic of the accepted clinical picture of neurosyphilis. Case 1 illustrates this point especially well. For 20 years this 64 -yearold woman had typical drop-attacks, seemingly of vertebrobasilar origin, and examination revealed no signs suggesting meningovascular disease. It was the blood W.R. examination alone which led to the correct diagnosis. A point to emphasize is that this patient has had no funther drop-attacks in a sixmonth follow-up period after completion of a standard course of penicillin.

Case 2 presented as organic dementia with an episode of visual hallucination and had bilateral corticospinal signs. He had abnormal pupils only inasmuch as there was slight reduction in the reaction to light. The problem was the investigation of organic dementia without any genuine hint of the real disorder on examination. The finding of positive serology in Cases 3 and 6 came as a complete surprise and there was certainly no clinical indication of neurosyphilis.

Case 5 was almost certainly suffering from tabes dorsalis, but the presence of diabetes mellitus and the age of the patient made interpretation difficult. Critchley (1931) noted that sensory complaints were common in old age and found that vibration sense and even position sense could be lost peripherally. Furthermore, diabetic neuropathy in itself can cause areflexia with impairment of vibration and joint position sense in the legs. Case 4 should in retrospect have been diagnosed before serological examination, and Case 7 would probably have been diagnosed without much difficulty in the early part of the century. It is not without interest that when shown at two meetings of distinguished neurologists and physicians only one neurologist diagnosed this young man's condition accurately and then in a rather apologetic manner. This boy was clearly suffering from congenital taboparesis, which is now a very rare syndrome.

Several lessons may be learnt from this small series of cases. First, our own awareness of neurosyphilis has been relatively lacking, and, second, neurosyphilis may be modified by courses of penicillin given for other reasons, making it then proportionately more difficult to diagnose. All our patients had had at least one course of penicillin or other antibiotics in recent years for minor ailments. The picture of neurosyphilis has changed for other genetic or immunological reasons over the years and the classical picture of neurosyphilis as described by Jonathan Hutchinson may now be a rare one, and even clinically misleading if modifications resulting from the factors to which we have referred are not appreciated. The present rise in primary syphilis (Lancet, 1967) may well leave a legacy of modified neurological disorder in the next few years, and our plea is thus the more germane.

\section{Summary}

Seven cases which presented atypical features of neurosyphilis are described. The reasons for the change in presentation are discussed and we wish to emphasize the value of performing routine Wassermann tests on all inpatients.

We are grateful to Dr. J. N. Walton and Dr. J. B. Foster for allowing us to study cases under their care. We would particularly like to thank Dr. Walton for his helpful criticism and advice.

\section{REFERENCES}

Critchley, M. (1931). Lancet, 1, 1119. Lancet, 1967, 2, 503. 